\title{
O Brasil diante da dinâmica migratória intra-regional vigente na América Latina e Caribe: Tendências, perspectivas e oportunidades em uma nova era
}

Brazil and the intraregional migratory dynamics in Latin America and the Caribbean: Trends, perspectives and opportunities in a new age

CARLOS FEDERICO DOMÍNGUEZ AVILA*

Rev. Bras. Polit. Int. 50 (2): 118-128 [2007]

\section{Introdução}

O propósito do presente artigo é caracterizar a participação brasileira na dinâmica migratória intra-regional vigente atualmente na América Latina. Especificamente são abordadas as tendências e perspectivas tanto das diásporas e dos fluxos de brasileiros em (ou para) países vizinhos, como das suas contrapartes latino-americanas e caribenhas residentes em território brasileiro. Também se enunciam algumas oportunidades, desafios e perspectivas futuras de tais expressōes de mobilidade humana.

Inicialmente é importante destacar que a noção de migração implica a mobilidade humana, isto é, seu deslocamento domiciliar temporário ou definitivo. $\mathrm{O}$ conjunto de motivaçôes ou incentivos que historicamente impulsionaram as migraçôes é bastante numeroso. Algumas migrações são guiadas por motivações voluntárias, outras são resultados de motivaçōes involuntárias e muitas vezes forçosas. De modo geral, as principais motivaçóes que estimulam as migrações internacionais contemporâneas incluem a aspiração de melhorar as condições de vida e de emprego, a reunificação familiar, os deslocamentos forçosos para preservar a integridade física, as desigualdades nos níveis de desenvolvimento, as assimetrias na distribuição dos benefícios oferecidos pela economia internacional, as carências de capital humano e conhecimentos, a curiosidade, entre outros. Também são relevantes as sinergias reais ou potenciais que surgem entre os chamados pull e push effects, isto é, entre as pressões migratórias endógenas e exógenas geradas pelo mundo atual (Held e outros, 1999; CEPAL, 2002).

* Professor do Mestrado em Ciência Política do Centro Universitário Euro-Americano - Unieuro e doutor em História pela Universidade de Brasília (cdominguez_unieuro@yahoo.com.br). 
América Latina é uma das regiōes do mundo com maior intensidade de migraçôes internacionais, especialmente no sentido Sul-Norte. O impacto socioeconômico, político, cultural e especificamente internacional deste fenômeno é sumamente relevante, tanto nos países de origem, quanto nos países de destino e de passagem dos emigrantes internacionais. Entretanto, o presente artigo se concentra na analise dos contingentes e dos fluxos migratórios intraregionais especificamente para o caso brasileiro - lembrando a sua condição de país emissor e receptor de migrantes (Villa e Martínez Pizarro, 2001; Domínguez Avila, 2006).

Convém adiantar que o estudo das migrações intra-regionais depende em grande medida dos dados coletados pelos censos demográficos nacionais. Tais censos oferecem valiosas informações sobre as características gerais e específicas dos movimentos migratórios internacionais entre países latino-americanos e caribenhos. Porém, os censos demográficos também demonstram limitações em quanto à periodicidade, à possibilidade de comparações entre censos de diferentes países da mesma região, à capacidade de identificar os estrangeiros em situação irregular, dentre outros aspectos.

Há que lembrar, todavia, que historicamente América Latina há sido uma região com grandes fluxos migratórios, inclusive intercontinentais, hemisféricos e binacionais. Em nível intra-regional, a Argentina e a Venezuela têm sido os principais pólos receptores ou de destino. E a Colômbia é, atualmente, o principal país de origem dos imigrantes intra-regionais (Villa e Martínez Pizarro, 2001).

\section{Diásporas e fluxos de cidadãos brasileiros nos países da América Latina e Caribe}

Tradicionalmente o Brasil foi um país essencialmente receptor de imigrantes. A partir do ano de 2003, entretanto, o número de emigrantes brasileiros superou o fluxo de estrangeiros interessados em residir no país. Ainda que não há números definitivos ou plenamente confiáveis, pesquisadores brasileiros especializados na temática migratória sugerem que aproximadamente quatro milhões de brasileiros e descendentes moram fora do país e outros quatro milhões viajam anualmente com outras finalidades (turismo, trabalho, negócios, educação, etc.); em ambos casos se trata de quantidades relativamente reduzidas de pessoas, recordando que atualmente a população total do país supera os 185 milhões de habitantes. Os principais destinos do crescente fluxo migratório brasileiro são os Estados Unidos, o Japão e certos países europeus.

No que diz respeito especificamente à emigração brasileira para países latinoamericanos e caribenhos, calcula-se que mais de 200 mil brasileiros moram em países vizinhos, especialmente no Paraguai, na Argentina, na Bolívia e no Uruguai - todos eles países membros ou associados do Mercado Comum do Sul (Mercosul). Tal quantidade converte o Brasil no quinto maior emissor intra-regional, sendo 
superado pelos emigrantes intra-regionais colombianos (600 mil), paraguaios (280 mil), chilenos (260 mil) e bolivianos (210 mil) (Baeninger, 2002).

Mais da metade dos brasileiros residentes na América Latina moram no Paraguai. Trata-se de pelo menos 150 mil pessoas - freqüentemente chamadas "brasiguaios". Esse importante contingente de brasileiros residentes em território paraguaio consolidou sua presença durante a década de 1970. Na época, os brasiguaios foram atraídos - pull effect-pela oferta de terras férteis com preços muito mais baratos que do lado brasileiro da fronteira comum. Também, pela chegada de muitos trabalhadores que participaram da construção da gigantesca barragem binacional de Itaipu, e que posteriormente tentaram melhorar as condiçôes de vida no vizinho país. De fato, depois de muitos esforços, um considerável número de brasileiros residentes no Paraguai logrou transformar-se em prósperos agricultores destacando-se pela sua massiva produção de soja para exportação.

Nos anos recentes, a situação migratória dos brasileiros residentes no Paraguai tem se caracterizado por uma crescente tensão. Especialmente preocupantes são os freqüentes questionamentos e ataques a latifundiários brasileiros por parte do Movimento dos Trabalhadores Rurais Sem Terra do Paraguai. Tais divergências, junto à presença de uma considerável quantidade de indocumentados brasileiros, entre outros temas, tem despertado a atenção dos governos e sociedades de ambos países. Acrescente-se o fato de que milhares de trabalhadores brasileiros, que vivem na cidade de Foz do Iguaçu, se deslocam diariamente para trabalhar na Cidade de Leste, especialmente nas atividades comerciais, já que essa última é uma importantíssima comunidade dedicada à reexportação de bens e serviços para o mercado brasileiro.

Um fenômeno muito parecido ao dos brasiguaios está acontecendo atualmente nas regióes norte e leste da Bolívia. Calcula-se que mais de 25 mil brasileiros se dedicam às atividades agropecuárias no território boliviano. Esse crescente fluxo Brasil-Bolívia é bastante recente e se mostra em um virtual contraponto da forte presença de bolivianos em algumas cidades brasileiras como São Paulo (Silva, 2001).

O perfil da maioria dos brasileiros residentes no Paraguai e na Bolívia sugere que se trata de migração familiar. A escolaridade desses dois grupos de emigrantes brasileiros é bastante limitada. Conseguintemente, suas inserçôes trabalhistas são fundamentalmente agrícolas e em atividades do setor informal da economia.

O contingente de brasileiros residentes na Argentina e no Uruguai é decrescente - com cerca 30 mil e 10 mil pessoas, respectivamente. Parte considerável das diásporas brasileiras residentes na Argentina e no Uruguai é constituída por pessoas idosas e mulheres jovens. A maioria das inserções trabalhistas desses concentra-se em atividades agrícolas, informais, serviços e, em menor medida, industriais.

Autoridades migratórias do Chile, da Venezuela, do Peru e, recentemente, da Colômbia reportam um crescente fluxo migratório brasileiro naqueles países. Entretanto, trata-se de números bastante modestos. Ainda menores são os 
contingentes de brasileiros residentes em países na região do Caribe - tais como o México, a América Central e as Antilhas. Nesse último caso não se inclui o crescente fluxo de cidadãos brasileiros que utilizam os países daquela sub-região norte da América Latina como virtuais "pontes" ou zonas de passagem com o propósito de alcançar território estadunidense ou canadense. Neste caso, trata-se de brasileiros que utilizam as rotas e procedimentos freqüentados por emigrantes indocumentados mexicanos, centro-americanos, caribenhos ou andinos que procuram novos horizontes em território estadunidense ou canadense (Villa e Martínez Pizarro, 2001).

Convém acrescentar que o governo brasileiro oferece assistência e proteção consular a todos os cidadãos que carentes de apoio, independentemente da situação administrativa, migratória ou ideológica das pessoas e/ou das diásporas brasileiras em questão. Portanto, a rede consular brasileira no continente americano - bem como em outros continentes - tem experimentado um sensível crescimento e profissionalização. Também foi criada uma Divisão de Atenção às Comunidades Brasileiras no Exterior dentro da estrutura do Ministério das Relaçōes Exteriores.

O fato de que a maioria dos brasileiros residentes na América Latina se concentre em países que formam parte ou são associados ao Mercosul - Brasil, Argentina, Bolívia, Chile, Paraguai, Peru, Uruguai, e Venezuela -, bem como afinidades históricas prevalecentes entre os diferentes países, permite que as autoridades locais ofereçam tratamento especial para os imigrantes procedentes dos países vizinhos. Note-se que existe o projeto da cidadania comunitária mercosulina, inspirada no modelo europeu e que implicaria, entre outros aspectos, na criação de um mercado trabalhista integrado, na livre mobilidade de trabalhadores e na redução de eventuais casos de ilegalidade e/ou abusos aos que poderiam estar sendo submetidos cidadãos brasileiros nos países vizinhos e vice-versa.

O referido projeto de cidadania comunitária mercosulina também deve atender a certas demandas socioculturais, políticas e econômicas especificamente das diásporas, tais como garantir a proteção dos direitos humanos das minorias étnico-lingüísticas brasileiras em um contexto predominantemente hispanoamericano. Afortunadamente, são praticamente inexistentes noticias sobre abusos sistemáticos e continuados contra os diretos socioculturais das diásporas brasileiras residentes nos países vizinhos. Outros temas sociais, políticos e econômicos de interesse dos imigrantes, tais como a seguridade social, aposentadorias, reconhecimento de titulações, etc., também precisam ser abordados no marco geral do processo de integração regional do Mercosul - especialmente no subgrupo de trabalho SGT 10 (Sant'Ana, 2001).

Outros casos particulares de migrações intra-regionais que dizem respeito aos cidadãos brasileiros incluem: (a) comunidades indígenas transnacionais que habitam simultaneamente e se deslocam freqüentemente entre os territórios do Brasil e de um outro Estado nacional, como por exemplo os guaranis e os 
ianomâmis - os primeiros radicados na região fronteiriça Brasil-Paraguai, e os segundos na região fronteiriça Brasil-Venezuela -; (b) brasileiros dedicados às atividades extrativistas irregulares de minérios preciosos em regióes de floresta tropical, especialmente na Venezuela, Guiana e Suriname - isto é, os garimpeiros-; e (c) o tráfico e a exploração sexual de mulheres brasileiras nas regiōes fronteiriça, especialmente nos casos do Paraguai, Bolívia e Suriname.

\section{Diásporas e fluxos de hispano-americanos e caribenhos para o Brasil}

Segundo o último Censo Demográfico, realizado em 2000, residiam cerca de 510 mil estrangeiros no Brasil. As comunidades portuguesa, japonesa, italiana e espanhola são as mais numerosas. Destaca-se o fato de que os estrangeiros representam $0,5 \%$ da população total do país.

$\mathrm{O}$ contingente total de hispano-americanos e caribenhos residentes no território brasileiro se aproxima de 130 mil - convertendo o país no quarto mais importante destino de imigrantes intra-regionais, somente superado pelas comunidades latinas e caribenhas residentes na Argentina (810 mil), na Venezuela (700 mil) e no Paraguai (150 mil). Essas quantidades representam menos de 0,1\% da população total do país e aproximadamente $15,5 \%$ do total dos estrangeiros residentes no Brasil.

As diásporas paraguaia, argentina, uruguaia e boliviana são, nessa ordem, as mais numerosas no território brasileiro - cada uma com mais de vinte mil integrantes (ver Quadro 1). Todavia, nos primeiros anos do século XXI tem que ser destacado o rápido crescimento absoluto e relativo especialmente dos paraguaios, bolivianos, peruanos e colombianos; e em menor medida também de venezuelanos, cubanos, e mexicanos. Complementarmente, vale destacar a estabilização e a redução dos contingentes de argentinos, uruguaios e chilenos. Infere-se que a grande maioria de hispano-americanos e caribenhos residentes no Brasil são naturais de países fronteiriços e sul-americanos, em geral.

\section{Quadro 1}

Latino-americanos e caribenhos residentes no Brasil, segundo Censo Demográfico 2000

\begin{tabular}{|c|c|}
\hline País & Estrangeiros residentes \\
\hline Argentina & 27.531 \\
\hline Bolívia & 20.388 \\
\hline Chile & 17.131 \\
\hline Colômbia & 4.159 \\
\hline Costa Rica & 238 \\
\hline Cuba & 1.343 \\
\hline
\end{tabular}




\begin{tabular}{|c|c|}
\hline País & Estrangeiros residentes \\
\hline Equador & 1.188 \\
\hline El Salvador & 480 \\
\hline Guatemala & 158 \\
\hline Guiana & 1.603 \\
\hline Haiti & 15 \\
\hline Honduras & 136 \\
\hline Jamaica & 57 \\
\hline México & 1.258 \\
\hline Nicarágua & 500 \\
\hline Panamá & 558 \\
\hline Paraguai & 28.822 \\
\hline Peru & 10.814 \\
\hline República Dominicana & 102 \\
\hline Suriname & 232 \\
\hline Uruguai & 24.740 \\
\hline Venezuela & 2.162 \\
\hline
\end{tabular}

Fonte: CELADE (2007).

No que diz respeito ao perfil socioeconômico dos imigrantes latinoamericanos residentes no território brasileiro destaca-se o fato de apresentarem uma clara maioria masculina, ser integrada por pessoas em idade produtiva ( 20 a 40 anos), com uma escolaridade intermediaria (e alta) e com inserções laborais bastante diversificadas. Esse último ponto é importante dado que as inserções trabalhistas incluem desde o trabalho servil e clandestino de bolivianos em oficinas de costura localizados especialmente na cidade de São Paulo, passando por um considerável número de pessoas trabalhando no setor de serviços, e até cargos de alta gerencia - especialmente em empresas transnacionais (Silva, 2001).

Convém mencionar que muitos hispano-americanos, bem como caribenhos de fala inglesa e francesa, têm encontrado nichos específicos de trabalho nas atividades de difusão das suas respectivas línguas e culturas de origem. As culturas inglesa e hispânica são particularmente demandadas por um crescente número de brasileiros.

O governo e a sociedade brasileira têm demonstrado ao longo de muitos anos o seu caráter de país receptivo - e não-refratário - de estrangeiros interessados em prosperar pelo próprio esforço. Assim, trata-se de uma sociedade fundamentalmente acolhedora e pouco discriminatória contra os estrangeiros. Entretanto, convém reafirmar que os fluxos especificamente de hispano-americanos e caribenhos para o Brasil são modestos e até decrescentes - com exceção dos casos acima mencionados 
(Barreto, 2001). Numa época de grandes êxodos de latino-americanos e caribenhos para outros países - particularmente para os Estados Unidos e para a União Européia -, o número de latinos que decidem procurar novos horizontes no Brasil é cada vez menor. Aparentemente tal reorientação dos fluxos migratórios globais, hemisféricos e intra-regionais se deva, basicamente, ao maior atrativo e demanda de força de trabalho latino-americana e caribenha que exercem outras sociedades, à vigência de uma legislação imigratória restritiva, a um sistema unificado de identificação e controle vigente no próprio Brasil, e ao modesto desempenho econômico e sóciopolítico experimentado pelo país nos últimos anos.

Note-se que não existem associações de residentes hispânicos em nível nacional, a semelhança das organizaçōes desta natureza nos Estados Unidos e outros países - contrastando com as diásporas dos árabes e japoneses, as quais têm associações de defesa e promoção dos seus diretos no Brasil. No que diz respeito às diferentes diásporas nacionais é importante mencionar suas características oscilatórias e basicamente cívico-recreativas, porém com baixa capacidade de articulação e mobilização social e política. Portanto, não é de se estranhar que suas reivindicaçôes logrem pouca ressonância além das autoridades do ramo, de alguns intelectuais especializados na temática e, especialmente, das instituições religiosas tais como a Pastoral do Imigrante da Igreja Católica - instituição que acompanha de forma mais sistemática a realidade dos imigrantes residentes em território brasileiro, inclusive aqueles em situação irregular ou indocumentados (Sprandel, 2001).

Usualmente a cada dez anos, o governo brasileiro concede anistia e a possibilidade de naturalização àqueles estrangeiros em situação irregular residentes no país - as duas últimas anistias aconteceram em 1988 e 1998. Tais processos de anistia migratória são precedidos de intensas e simpáticas campanhas de difusão nos meios de comunicação, convidando-os a se apresentar diante das autoridades competentes. Demanda-se a apresentação dos documentos pessoais, a declaração de emprego e o pagamento de certas taxas. Caso não existam antecedentes criminais ou algum outro impedimento, a anistia migratória e a autorização de residência temporária ou definitiva são concedidas. Alguns autores têm questionado os altos custos das taxas e o temor dos estrangeiros diante certos procedimentos burocráticos para atender à regularização migratória. Entretanto, vale enfatizar que, em geral, as autoridades do ramo - Política Federal, Ministério da Justiça e Justiça Federal - são bastante tolerantes, sensíveis e receptivas diante da difícil realidade de seres humanos que procuram novos horizontes no Brasil. Predomina um enfoque humanista com relação às minorias estrangeiras, das que se espera como mínimo uma integração construtiva à realidade nacional (Barreto, 2001; Sprandel, 2001).

A naturalização brasileira é uma alternativa para aqueles estrangeiros com pretensões de radicar-se definitivamente no país, sobretudo no caso de estrangeiros cassados com conjugues ou filhos brasileiros. Sem esquecer que a naturalização permite exercer a cidadania integral, isto é, civil, social e política. 
Convém insistir que os cidadãos oriundos dos países que integram o Mercosul têm um trato preferencial por parte das autoridades brasileiras, devido aos acordos inter-governamentais específicos. O projeto para criar uma cidadania comunitária seguindo o modelo europeu é, quiçá, a principal proposta no concernente à temática no momento. Nessa hipótese predominaria o principio da livre mobilidade de trabalhadores, diretos sociais compartilhados e convergentes, o reconhecimento de títulos e de outros documentos, política migratória conjunta com relação ao fluxo de pessoas procedentes de terceiros países, um enfoque humanístico do fenômeno migratório global, entre outros importantes aspectos (Sant'Ana, 2001; CEPAL, 2002).

Finalmente, uma tendência imigratória particularmente recente e que há cobrado certa notoriedade nos meios de comunicação brasileiros nos últimos anos está vinculada ao direto de asilo e refugio para colombianos que procuram salvar a vida em virtude da situação de conflito armado interno predominante naquele país. Em geral, o governo brasileiro é coerente com o direto internacional humanitário e concede tal proteção - seja temporária ou definitiva. Um tratamento semelhante recebem cidadãos de origem cubana que decidem radicarse em território brasileiro. Naturalmente tais benefícios não são concedidos aos estrangeiros com antecedentes criminais em seus países de origem ou no Brasil.

\section{Considerações finais}

O Brasil é um país importante na dinâmica migratória intra-regional vigente na América Latina e Caribe. Aproximadamente 200 mil cidadãos brasileiros e descendentes vivem nos países vizinhos - conseqüientemente, trata-se do quinto maior emissor intra-regional, sendo que a maioria reside em território paraguaio. E cerca de 130 mil latino-americanos e caribenhos moram no Brasil - quarto receptor intra-regional, com destaque para as diásporas paraguaia, argentina, uruguaia e boliviana.

Ainda que reconhecendo especificidades nacionais, tanto as diásporas brasileiras residentes nos países vizinhos como as estrangeiras residentes no Brasil desfrutam de tratamento preferencial, humanístico, tolerante e compassivo. Existem pouquíssimos casos de xenofobia, racismo ou abusos sistemáticos das sociedades e governos hospedes de uns e outros. Tal situação também se aplica ao particular caso dos brasileiros que, de forma mais ou menos clandestina, atravessam território centro-americano e mexicano com destino aos Estados Unidos.

$\mathrm{O}$ fato de que a maioria das diásporas intra-regionais brasileiras no exterior e latino-americanas no Brasil tenham como origem ou destino os países membros do Mercosul, permite e/ou favorece oferecer um tratamento preferencial para todos. Insistindo, novamente, no projeto para a constituição de uma cidadania comunitária que traria enormes benefícios, erigindo-se em exemplo positivo para a gestão migratória continental e global. 
Convém recordar, todavia, que a dinâmica migratória intra-regional também implica em custos, desafios e oportunidades nos países emissores, receptores e de passagem. Entre os custos derivados da migração intra-regional destacamse: a desintegração familiar, as dificuldades e incertezas que necessariamente surgem dos deslocamentos internacionais e da adaptação à cultura dominante nas comunidades de destino ou receptoras - bem como aos novos ambientes de trabalho. Quando se trata de pessoas indocumentadas ou irregulares os custos psicológicos e sociais também são elevados.

Entre os desafios colocados aos países emissores, receptores e de passagem pelo fenômeno migratório intra-regional certamente ressaltam: (a) fomentar um fluxo migratório ordenado, legal, disciplinado e congruente com a soberania, com a integridade territorial e com os interesses nacionais de cada Estado; (b) lutar contra as atividades delitivas vinculadas ao tráfico de pessoas e aos abusos contra os diretos humanos dos migrantes; (c) colocar o debate sobre a migração internacional como prioridade da agenda regional; (d) promover uma circulação e intercambio de recursos humanos qualificados entre os países do continente, procurando diminuir e modificar o impacto da chamada "fuga dos cérebros"; (e) repensar e avançar em esferas da vida vinculadas ao fenômeno da migração, tais como a passagem das fronteiras, a previdência social dos emigrantes, o reconhecimento dos estudos e qualificações profissionais; (f) a facilitação e redução dos custos das transferências financeiras (ou remessas) enviadas pelos emigrantes aos seus familiares nos países de origem; e (g) em geral, assegurar a preservação dos diretos humanos dos emigrantes e seus descendentes residentes nos países vizinhos.

No que diz respeito às oportunidades derivadas do fenômeno migratório intra-regional vale citar as seguintes: (a) a migração permite abrir novos espaços de diálogo, de aproximação e de integração social, econômica e política entre os países, sociedades e culturas que formam parte da América Latina e Caribe; (b) historicamente a migração intra-regional foi utilizada como uma virtual "válvula de escape" ao permitir uma certa descompressão das tensões geradas pelo desemprego e pela exclusão social; (c) a migração internacional pode favorecer as transferências de tecnologia e a cooperação Sul-Sul; e (d) a migração internacional, em geral, se erige em uma forma legítima de mobilidade social ascendente.

As perspectivas futuras da contribuição brasileira na dinâmica migratória intra-regional latino-americana e caribenha são promissórias, ainda que certamente modestas tanto em termos de expulsão como de recepção de migrantes. Dificilmente a dinâmica intra-regional vigente poderá comparar-se com os grandes fluxos de sentido Sul-Norte, que inclui aos contingentes de latino-americanos e caribenhos que procuram novos horizontes nos Estados Unidos, na União Européia e outros países de alto desenvolvimento humano. Conseqüentemente, a migração intra-regional continuará tendo certa relevância, especialmente nos casos de movimentos transitórios, temporários ou fronteiriços. 
Inclusive nessa última hipótese, as principais autoridades dos países de origem, de destino e de passagem terão que se preparar e repensar algumas das suas aproximaçôes teóricas, práticas e políticas vinculadas à questão migratória intra-regional, procurando favorecer o desenvolvimento de fluxos migratórios ordenados, regulares, seguros e vantajosos para todas as partes.

Finalmente, convém realçar que uma tarefa fundamental e iniludível de todas as sociedades e Estados latino-americanos na atualidade é justamente oferecer condiçōes de vida e de trabalho cada vez mais dignas, honrosas e satisfatórias para seus cidadãos. Normalmente as pessoas optam por migrar quando chegam à conclusão de que o país de origem não mais oferece condições básicas de bemestar econômico, político e social. Avançar no que diz respeito às condiçôes gerais para que os cidadãos não necessitem (ou sejam forçados a) abandonar ou país é certamente a melhor opção possível. Afinal, se realmente a população é a principal riqueza de um país, parece evidente que a emigração de talentos, de mentes e de braços representa uma perda - temporária ou definitiva - que dificilmente poderá ser compensada no futuro.

Recebido em 30 de março de 2007 Aprovado em 12 de novembro de 2007

\section{Bibliografia}

BAENINGER, Rosana, La migración internacional de los brasileños: características y tendencias, Santiago de Chile: CELADE/CEPAL, 2002.

BARRETO, Luiz Paulo Teles Ferreira, "Considerações sobre a imigração no Brasil contemporâneo”, em CNPD: Migraçôes Internacionais/ Contribuiçôes para Políticas, Brasília: Governo Federal, 2001, pp. 63-71.

CELADE, "IMILA: Investigación de la Migración Internacional en Latinoamérica”, Santiago de Chile: CEPAL, 2007, na Internet: http://www.eclac.cl/migracion/imila/.

CEPAL, Globalização e desenvolvimento. Nações Unidas, Santiago de Chile, 2002.

DOMÍNGUEZ AVILA, Carlos Federico, "Migración, Globalización e Relaciones Internacionales: En busca de nuevas interpretaciones fundamentadas en evidencias latinoamericanas recientes", em María Ileana García Gossio (organizadora): Los nuevos escenarios de la migración: causas, condiciones, consecuencias, México: Fundación Böll, 2006, pp. 197-212.

HELD, David e outros, Global transformations/ Politics, Economics and Culture. Stanford University Press, Stanford, 1999.

SANT'ANA, Marcílio, "Livre Circulação de Trabalhadores no Mercosul?”, em CNPD: Migrações Internacionais/ Contribuiçōes para Políticas, Brasília: Governo Federal, 2001, pp. 73-93.

SILVA, Sidney A. da, "Hispano-americanos no Brasil: Entre a cidadania sonhada e a concedida", em CNPD: Migraçôes Internacionais/ Contribuiçôes para Políticas, Brasília: Governo Federal, 2001, pp. 489-501. 
SPRANDEL, Márcia, "Migrações internacionais e a sociedade civil brasileira”, em CNPD: Migraçōes Internacionais/ Contribuiçōes para Políticas, Brasília: Governo Federal, 2001, pp. 547-562.

VILLA, Miguel, e MARTÍNEZ PIZARRO, Jorge, "Tendencias y patrones de la migración internacional em América Latina y el Caribe”, em CEPAL: La migración internacional y el desarrollo en las Américas, Naçōes Unidas, Santiago de Chile, 2001, pp. 21-60.

\section{Resumo}

O artigo explora as contribuições brasileiras na dinâmica migratória intra-regional vigente entre países da América Latina e Caribe. A dinâmica migratória intra-regional inclui as diásporas e os fluxos de brasileiros residentes nos países vizinhos e suas contrapartes latinoamericanas e caribenhas residentes no Brasil. Verifica-se que o Brasil é o quinto emissor e quarto receptor de migrantes intra-regionais.

\section{Abstract}

The article explores Brazilian contributions to the intraregional migration dynamic among Latin American and Caribbean countries. Part of this dynamic are Diasporas and the flow of Brazilian citizens living in neighboring countries and vice-versa-Latin-American and Caribbean citizens living in Brazil. Brazil is the fifth country with national in neighborhoods countries, and the fourth destiny of intra-regional immigrants.

Palavras-chaves: Migrações intra-regionais; Brasil; América Latina e Caribe.

Key words: Intraregional migrations; Brazil; Latin America and Caribbean. 